http://jmscr.igmpublication.org/home/

ISSN (e)-2347-176x ISSN (p) 2455-0450

crossref DOI: https://dx.doi.org/10.18535/jmscr/v7i11.148

Journal Of Medical Science And Clinical Research

\title{
Computed tomography texture analysis of Ameloblastoma
}

\author{
Authors \\ Dr Awadhesh Tiwari ${ }^{1}$, Dr N.Suresh, MD General Medicine ${ }^{2}$ \\ ${ }^{1}$ Associate Professor, Department of Radiology, Lumbini Medical College, Palpa, Nepal \\ ${ }^{2}$ Assistant Professor, Dept. of Medicine, Govt. Theni Medical College, Theni
}

\begin{abstract}
Ameloblastoma is a benign tumor most commonly seen in mandible. There are various methods to diagnose ameloblastoma of which biopsy is a standard procedure. However, biopsy is an invasive method for diagnosing ameloblastoma which can cause discomfort to the patient. Hence, CT texture analysis is a non-invasive diagnosing technique which can be used to differentiate ameloblastoma from other cystic lesions. Hence, this article gives an eye view regarding the CT texture analysis of ameloblastoma and its accuracy to differentiate from other lesions.

Keywords: Ameloblastoma, Computed tomography, texture analysis.
\end{abstract}

\section{Introduction}

Ameloblastoma is a benign, rare, slow-growing, locally involving neoplasm of odontogenic origin involving most commonly mandible normally found to be associated with impacted wisdom teeth $^{1}$. Although it is considered a benign tumor its clinical behavior lies between benign and malignant ${ }^{1}$. The various forms of occurrence have resulted in the development of rational basis of treatment.

The diagnostic evaluation of ameloblastoma includes imaging and biopsy ${ }^{5,7}$. Plain $\mathrm{x}$ rays lack the sensitivity and specificity for the evaluation of extent of bone and soft tissue invasion, henceforth $3 \mathrm{~d}$ imaging analysis could give a detailed view of invasion of the lesion ${ }^{4}$. Computed tomography can be used as a reliable imaging diagnostic modality for well defined unilocular or multilocular expansile lesions and is also useful to detect the amount of cortical destruction which is very useful to plan the surgical extension of the lesion ${ }^{1}$.
MRI provides potentially a better view on poorly defined ameloblastomas especially desmoplastic ameloblastomas $^{1,7}$. PET CT is used in metastatic ameloblastomas $^{2}$.

Texture analysis is a post processing technique that extracts information native to image data that is not apparent on visual inspection of images ${ }^{2}$. These techniques ultimately provides quantitative means of extracting image features that are useful for comparative analysis ${ }^{2,3}$. In the past several years, CT texture analysis has been investigated in oncology imaging include head and neck cancers to predict human papilloma virus status which is important for treatment aspect ${ }^{2}$. However, recent studies indicates that CT texture analysis can be used as a new biomarker for advanced oncologic imaging $^{2,3}$.

\section{Methods and Methodology}

A thorough search was made through PubMed, EMBASE, GOOGLE SCHOLAR and Cochrane 
database from 2000 until august 2019. Relevant articles of case series, review articles, retrospective study was included.A thorough literature search was done using keywords "Computed tomography", "ameloblastoma", "imaging" and "texture analysis.

\section{Discussion}

Ameloblastoma is slow growing, rare benign tumor which is seen most commonly in the mandible.

A study by Anita gohel et al in 2018 concluded that multi detected row computed tomography can be used for imaging head and neck lesions as it provides integrated anatomic and functional high resolution image with low radiation doses ${ }^{2}$. But however studies by Akira baba et al in 2019 concluded that MRI could be used for evaluating jaw lesions whose cystic or solid characteristics could not be distinguished with CT or radiograph $^{3}$.

A texture analysis study by Farzana et al in 2014 concluded that energy parameter was very less for ameloblastoma in CT as compared to dentigerous cyst and keratocyst ${ }^{4}$. A study by Masafomi oda et al in 2019 concluded that CT texture analysis can be useful noninvasive tool to differentiate among cystic and cystic appearing odontogenic lesions ${ }^{2}$.

Farzana shahar et al in 2014 classified the cysts based on texture analysis and found accuracy of $85.7 \%$ for ameloblastoma, $80 \%$ for keratocyst, $81.81 \%$ for dentogerous cyst ${ }^{4}$.

\section{Conclusion}

CT has proved to be a very useful imaging modality for odontogenic lesions. But however differentiating between various lesions could be possible with high end contrast imaging technique as well as with reduced exposure to the patient. But however there are only limited studies in CT texture analysis of various odontogenic lesions and hence more studies are required in order to help the clinician in the accurate diagnosis of the lesion.

\section{References}

1. Yazdi E, Seyed Mm, Foroughi R. Desmoplastic ameloblastoma (a hybrid variant): report of a case and review of the literature.

2. Gohel A, Oda M, Katkar AS, Sakai O. Multidetector row computed tomography in maxillofacial imaging. Dental Clinics. 2018 Jul 1;62(3):453-65.

3. Baba A, Ojiri H, Minami M, Hiyama T, Matsuki M, Goto TK, Tatsuno S, Hashimoto K, Okuyama Y, Ogino N, Yamauchi H. Desmoplastic ameloblastoma of the jaw: CT and MR imaging findings. Oral radiology. 2019 Apr 2:1-7.

4. Banu AF, Kayalvizhi M, Arumugam B, Gurunathan U. Texture based classification of dental cysts. In2014 International Conference on Control, Instrumentation, Communication and Computational Technologies (ICCICCT) 2014 Jul 10 (pp. 1248-1253). IEEE.

5. Smith HL, Rosenblatt AJ, Suen WW, Owen H, Ahern BJ. Maxillary unicystic ameloblastoma in a 6- week- old filly evaluated with computed tomography. Australian veterinary journal. 2017 Aug;95(8):299-303.

6. Li D, Yang Z, Chen T, Guan C, Wang F, Matz EL, Zhang Y, Ji P. 3D cone beam computed tomography reconstruction images in diagnosis of ameloblastomas of lower jaw: A case report and mini review. Journal of X-ray science and technology. 2018 Jan 1;26(1):133-40.

7. McClary AC, West RB, McClary AC, Pollack JR, Fischbein NJ, Holsinger CF, Sunwoo J, Colevas AD, Sirjani D. Ameloblastoma: a clinical review and trends in management. European Archives of Oto-Rhino-Laryngology. 2016 Jul 1;273(7):1649-61. 